\title{
The Long-Term Impacts of Medicaid Exposure in Early Childhood: Evidence from the Program's Origin*
}

\author{
Michel H. Boudreaux ${ }^{\mathrm{a}}$, Ezra Golberstein ${ }^{\mathrm{b}}$, Donna D. McAlpine ${ }^{\mathrm{c}}$
}

a (Corresponding Author) Department of Health Services Administration, School of Public Health, University of Maryland. 3310 School of Public Health Building, College Park, MD 20742 mhb@umd.edu. 301-405-6118. ${ }^{\dagger}$

${ }^{\mathrm{b}}$ Division of Health Policy and Management, School of Public Health and Minnesota Population Center, University of Minnesota. 420 Delaware Street SE, 15-213 PWB MMC 729 Minneapolis, MN 55455, United States. egolber@umn.edu

${ }^{\mathrm{c}}$ Division of Health Policy and Management, School of Public Health, University of Minnesota. 420 Delaware Street SE, 15-232 PWB MMC 729 Minneapolis, MN 55455, United States. mcalp004@umn.edu

\footnotetext{
* This project was supported by an Interdisciplinary Doctoral Fellowship from the University of Minnesota, by grant number R36HS021690 from the Agency for Healthcare Research and Quality, and by the Minnesota Population Center Grant from the Eunice Kennedy Shriver National Institute for Child Health and Human Development (5R24HD041023). The content is solely the responsibility of the authors and does not necessarily represent the official views of the Agency for Healthcare Research and Quality or any other funder. The collection of data [The Panel Study of Income Dynamics] used in this study was partly supported by the National Institutes of Health under grant number R01 HD069609 and the National Science Foundation under award number 1157698. Portions of the paper are based on restricted use data from the National Health Interview Survey. The findings and conclusions drawn from these data are those of the authors and do not necessarily represent the views of the Research Data Center, the National Center for Health Statistics, or the Centers for Disease Control and Prevention. Doug Almond, Hillary Hoynes, Amy Finkelstein, Martha Bailey and Andrew Goodman-Bacon generously provided data from the 1960's and 1970's and guided us in their use. We are grateful to Marianne Bitler, Aaron Sojourner, David Frisvold, Martha Bailey, Bryan Dowd, and seminar participants at the Human Capital Research Collaborative, the Rethinking Barker Conference, the American Society of Health Economists Biennial Conference, the AcademyHealth Annual Research Meeting, Virginia Commonwealth University, University of Kansas, University of Maryland, George Washington University and Vanderbilt University for their helpful comments. We also thank the editor and the anonymous reviewers.

${ }^{\dagger}$ The majority of work for this paper was completed while this author was affiliated with the Division of Health Policy and Management, School of Public Health, University of Minnesota.
} 


\begin{abstract}
This paper examines the long-term impact of exposure to Medicaid in early childhood on adult health and economic status. The staggered timing of Medicaid's adoption across the states created meaningful variation in cumulative exposure to Medicaid for birth cohorts that are now in adulthood. Analyses of the Panel Study of Income Dynamics suggest exposure to Medicaid in early childhood (age 0-5) is associated with statistically significant and meaningful improvements in adult health (age 25-54), and this effect is only seen in subgroups targeted by the program. Results for economic outcomes are imprecise and we are unable to come to definitive conclusions. Using separate data we find evidence of two mechanisms that could plausibly link Medicaid's introduction to long-term outcomes: contemporaneous increases in health services utilization for children and reductions in family medical debt.
\end{abstract}

Keywords: Medicaid; health and human capital 


\section{Introduction}

Poor health in early life has long-term consequences, including reduced health and socioeconomic status in adulthood (Almond and Currie, 2010; Currie and Rossin-Slater, 2014). Recent research highlights the possibility that health investments in the early childhood period may yield long-run returns (Hoynes et al., 2014; Bharadwaj et al., 2013). With few exceptions, the literature has not considered the long-term impact of large public programs that specifically target child health. The United States (U.S.) spends significant sums on in-kind transfers of medical care, often with the explicit goal of influencing low-income children's future health and socioeconomic prospects. ${ }^{3}$ Considerable evidence exists on the short-term effects of these programs, but little is known about whether they have long-term benefits.

This paper examines the long-term effect of Medicaid, the main source of public health insurance for children and pregnant women in the U.S. The program finances $48 \%$ of all deliveries and provides coverage to $35 \%$ (28 million) of all children under the age of 19 (Markus et al., 2013; SHADAC, 2013). The program consumes $8 \%$ of all federal spending and $16 \%$ of state budgets, on average (Kaiser Family Foundation, 2012).

Medicaid could influence the long-term outcomes of children by increasing access to effective medical interventions that improve childhood health in ways that persist into adulthood. Take-up of Medicaid also could reduce a family's inframarginal medical spending, freeing up resources that are subsequently directed towards other investments in children. Evaluations of Medicaid's short and medium-term effects suggest that Medicaid encourages consumption of medical services, improves health, and potentially reduces the risk of catastrophic out-of-pocket spending, for very low-income children (Howell and Kenny, 2012; Currie and Gruber, 1996a,b; Currie et al., 2008; Sommers and Oellerich, 2013). These outcomes are known to shape the evolution of health and socioeconomic status.

We add to this literature by studying Medicaid's long-term impact, leveraging the program's staggered adoption across the states and comparing households that were more and

\footnotetext{
${ }^{3}$ For example, while advocating on the Senate floor for the creation of the State Children's Health Insurance Program, Sen. Edward Kennedy remarked, "Providing health care for children is sound public policy and also sound economics. It's an investment in the future" (105 Congressional Register S134). That same year Sen. Kennedy remarked in support of the Early Childhood Development Act, "Recent research has clearly demonstrated what parents and others have intuitively known for generations: that experiences in the early childhood years lay the foundation for much of later development... Quality child care, quality nutrition, and quality health care can make all the difference in enabling infants and children to reach their full potential and become contributing members of society" (105 Congressional Register S4501).
} 
less likely to have received Medicaid benefits. Medicaid's adoption, which occurred mainly between 1966 and 1970, created meaningful variation in early life exposure to the program for birth cohorts that are now in midlife, which is plausibly exogenous with respect to midlife health and economic outcomes. Furthermore, eligibility rules created additional variation in Medicaid participation that we use to isolate Medicaid's impact. Using the Panel Study of Income Dynamics we track the 1955-1980 birth cohorts from conception into adulthood (age 25-54). We use state-of-birth and county-of-birth identifiers to link individual records with Medicaid adoption dates and a detailed set of area-by-year controls that describe characteristics of health care markets and the availability of other public programs.

Our results indicate that for low-income children exposure to Medicaid eligibility throughout the period from conception to the $6^{\text {th }}$ birthday is associated with a 0.35 standard deviation improvement in adult health (age 25-54), measured using a composite index that combines information on high blood pressure, diabetes, heart disease/heart attack, and obesity. Models that more closely approximate the effect of the treatment-on-the-treated suggest large effects, a 3.15 standard deviation reduction in the composite condition index. We also examined Medicaid's long-term impact on economic outcomes, but our results are very imprecise. At a 95\% confidence level, our treatment-on-the-treated model can only rule out effects larger than a 5 standard deviation increase in adult economic well-being, measured using a composite index of income-to-poverty ratios, educational attainment and family wealth. We also use historical survey data to document two potential mechanisms through which the program's introduction might have affected long-run outcomes: health services use during early childhood and medically-related family economic strain.

Our analysis suggests that the value of covering expectant mothers and young children through the Medicaid program extends beyond contemporaneous measures of health and financial hardship. This finding has implications for cost-benefit valuations of Medicaid and may also speak to the potential benefits of current health insurance expansions. By focusing on a specific policy action to improve health among disadvantaged children, this paper also contributes to the literature on the long-run impacts of early life health which has focused primarily on the developmental consequences of early life health insults. Specifically, we are one of the first to examine of the long-run benefits of Medicaid coverage in childhood in addition to 
the short-term effects of Medicaid's introduction on health service utilization and financial outcomes.

The paper is organized as follows. In Section 2 we review evidence on Medicaid's impact over the medium term which suggests that the health benefits of Medicaid may be persistent. We then describe the links between childhood health, health investments, and adult attainments to help motivate our focus on the early childhood period. Next, we turn to the setting of the current study by describing the institutional background of Medicaid's introduction. In Section 3 we describe data and methods, in Section 4 we present main results, and in Section 5 we examine two mediating mechanisms. Section 6 concludes.

\section{Background}

\subsection{Medium-Term Impacts of Medicaid}

Medicaid coverage in childhood could improve childhood health by reducing the out-ofpocket price of health care which leads to increased utilization of effective medical interventions. As we describe in section 2.2, improvements in childhood health facilitated by Medicaid could play an important role in determining the risk of later disease, human capital accumulation, and adult economic outcomes. Obtaining Medicaid coverage could also free up a household's inframarginal health care spending which could be subsequently directed toward investments in children (Sommers and Oellerich, 2013; Shaefer et al., 2011). ${ }^{4}$ Increased economic resources in early childhood are known to improve long-run outcomes by increasing child investment and reducing psychological stress (Duncan et al., 2010).

Empirical evidence from a small set of papers supports the idea that Medicaid coverage in early childhood is associated with downstream benefits - specifically with improved health in later childhood. Using a simulated eligibility instrument Currie, Decker, and Lin (2008) show that eligibility at ages 2-4 is associated with improved self-reported health at ages 9-17. Likewise, using a regression discontinuity approach, Wherry and Meyer (2015) show that increased cumulative eligibility between the ages of 8 to 14 is associated with declines in

\footnotetext{
${ }^{4}$ While both Sommers and Olerich (2013) and Shaefer, Grogan, and Pollack (2011) suggest that Medicaid is associated with a meaningful level of implicit cash transfers (on the order of $\$ 1,500 /$ year), it has been difficult to tie these transfers to increased spending on non-medical goods. Leininger, Levy, and Schanzenbach (2010) find modest increases in transportation and retirement spending in response to expanded public insurance for children and Saloner (2013) finds no evidence of a reduction in food insecurity.
} 
mortality for black children at ages 15-19. They find smaller effects for whites who were substantially less likely to be eligible for Medicaid. Some evidence suggests that public health insurance in early childhood is associated with increased academic performance. Levine and Schanzenbach (2009) find that eligibility for public health insurance at birth is associated with modest gains in reading, but not math scores for 9 and 14 year olds. The only other study to examine the medium-term effects of Medicaid coverage in childhood found that gaining Medicaid eligibility at ages 5-18 is associated with improved contemporaneous utilization of preventative care, but that a 5-year lagged measure of eligibility was not associated with improvement in self-reported health, missed school days, or obesity (De La Mata, 2012).

This small, but important set of papers suggests that the value of Medicaid may extend beyond contemporaneous measures of health and financial well-being. We build on those papers by extending the follow up period to midlife.

Four concurrent papers also consider Medicaid's longer-term impact using program expansions during the 1980's and 1990's as a source of identifying variation. Using detailed administrative records, Brown, Kowalski, and Lurie (2014) find that childhood exposure to Medicaid increases wages, decreases reliance on government transfers, and decreases mortality by age 31. Cohodes and colleagues (2015) find evidence of improved educational attainment. Wherry et al. (2015) find that Medicaid exposure in early life reduces hospitalization and emergency department utilization for chronic conditions for 25 year olds and Miller and Wherry (2015) find that Medicaid coverage during the prenatal period reduces obesity and chronic conditions when affected cohorts reach their mid-20's. Our work complements these papers and also has distinct strengths. Because we study the program's introduction, rather than its later expansions, we are able to track cohorts further into adulthood (the average age in our sample is 38), when effects could be more pronounced. Unlike Cohodes et al. (2015), Wherry et al. (2015), and Miller and Wherry (2015) we observe socioeconomic status in early childhood, which allows us to examine subgroups that were specifically targeted by eligibility rules. We also are able to use historical survey data to examine two potential mediators of the effect of Medicaid's introduction on long-run outcomes, namely health services utilization and medically-related household financial strain. 


\subsection{Early Childhood Health and Long-Run Outcomes}

A compelling body of work across different disciplines shows that early childhood, starting in the fetal period, is a particularly sensitive time in which shocks or investments can have important long-term consequences for adult chronic disease risk (Shonkoff et al., 2009; Currie and Almond, 2011; Ben-Shlomo and Ku, 2002). The empirical evidence supporting the importance of early childhood is robust and growing, but the causal mechanisms behind these relationships are not fully understood. A prominent explanation is the fetal origins hypothesis, which, strictly interpreted, suggests that malnutrition during the fetal period can disrupt the development of internal organs and physiological processes and result in increased risk of heart disease, diabetes, and obesity (Barker, 1997). The developmental principles underlying the fetal origins hypothesis have been extended to other harmful fetal exposures such as environmental toxins and maternal disease (Gluckman et al., 2007; Almond and Currie, 2010). More broadly, economists have conceptualized early childhood as a particularly sensitive period because it lays the developmental groundwork that future investments need to be fully productive (Cunha and Heckman, 2006).

Correlational evidence on early life health and long-run health outcomes dates back to the 1930's (Kermack et al., 1934), but more recent work takes advantage of natural experiments in which exposures are plausibly unrelated to unobserved variables such as genetic predisposition or family background characteristics. For example, children exposed to famine events or diurnal fasting in utero and in the first few years of life have increased risk of disability, heart disease, diabetes, obesity, and cancer (Chen and Zhou, 2006; Almond and Mazumder, 2011; Schulz, 2010). Exposure to influenza during the prenatal period and the first few years of life, compared to no exposure and exposure in later years of childhood, has also been linked to disability and heart disease in adulthood (Almond, 2006; Mazumder et al., 2009). In addition to cohort

comparisons, sibling differences in birth weight (a common proxy for the fetal environment) reveal that low birth weight infants have 2-6 times larger hazard rates of asthma, hypertension, heart disease and stroke in adulthood (Johnson and Schoeni, 2011).

Evidence on the downstream economic impacts of early health shocks comes from cohort comparisons driven by natural experiments and from studies of intra-twin differences in birth 
weight that hold constant common genetic factors and family environments. ${ }^{5}$ For example, using a dataset of Norwegian twins, Black, Devereux, and Salvanes (2007) estimate that a 10\% increase in birth weight is associated with a 1 percentage point increase in high school completion, a 3 percentage point increase in full time work, and a 1 percent increase in earnings. Similar findings from twin fixed effects models have been reported in the U.S. context (Figlio et al., 2014; Royer, 2009). To put these magnitudes in perspective, Currie (2011) demonstrates that that the correlation between birth weight and wages at age 24-27 is roughly the same as the correlation between academic test scores and wages.

Evidence of the long-run effects of poor childhood health has spurred interest in the ability of child health investments to promote health and economic attainment in adulthood. Recent studies in this area largely focus on economic outcomes. Bharadwaj, Løken, and Neilson (2013) show that the infants born just below the very low birth weight threshold, who receive more intensive medical care compared to their slightly heavier counterparts due to medical guidelines, score higher on standardized academic tests during school age. Randomized NurseFamily visitation interventions that provide pre-natal and early life health services have been shown to improve economic attainment by young adulthood (Eckenrode et al., 2010). Bhalotra and Venkatarmani (2011) find that sulfa antibiotic use, which dramatically decreases the incidence of childhood pneumonia, is associated with higher education and income and decreased disability in adulthood. Lee (2013) finds that mandatory school vaccination laws increase high school completion, labor force participation, wages, and returns to schooling. Another study finds that the improvements in access to health care for black infants in the U.S. that emerged from hospital desegregation resulted in significant gains in cognitive skills measured at the transition to adulthood (Chay et al., 2009). These studies lend credence to the notion that improvements in access to health care in early childhood can improve long-run economic outcomes.

The most pertinent study to the present paper in terms of methodology is Hoynes, Schanzenbach, and Almond's (2014) (henceforth HSA) evaluation of the food stamp program. Using data from the PSID and treatment variation brought about by the program's gradual implementation across the country, they find that access to food stamps through the duration of

\footnotetext{
${ }^{5}$ It should be noted that while twin fixed effects studies hold constant a large share of the parental environment it remains possible that parents adjust their investments in response to the health of the child.
} 
early childhood (ages 0-5), compared to its absence, is associated with a 0.3 standard deviation improvement in an index of adult health conditions. They also find that access to food stamps improved socioeconomic outcomes in women, but not men.

Our paper departs from previous work on health investments by considering the longterm impacts of public health insurance in a low income population. While literature on Medicaid's health effects is mixed, Medicaid in childhood has previously been shown to increase access and use of health services and to improve objective measures of health such as mortality and avoidable hospitalizations (see review in Howell and Kenny, 2012). In this paper we examine whether Medicaid exposure in early life is associated with improved health and economic status in adulthood. Medicaid is a particularly important intervention to study because it is a large program affecting millions of pregnant women and children. It constitutes $15 \%$ of all national health care expenditures ( $\$ 407$ billion), it plays an important role in coverage expansions included the Affordable Care Act, and it is of consistent interest to state and federal policy makers.

\subsection{The Institutional Background of Medicaid's Introduction}

Individuals' and families' participation in Medicaid is voluntary and it is likely that unobserved factors correlated with enrollment decisions are also correlated with a child's longterm outcomes. To overcome this endogeneity we examine exposure to Medicaid policy rather than participation in the program. Specifically, our identification strategy uses Medicaid's staggered implementation across the states in combination with individual-level variation in the probability to participate in Medicaid which was influenced by eligibility rules and long-standing state differences in public program generosity. This section describes the institutional arrangements of Medicaid's introduction and introduces our analytic approach.

Although all states now participate in Medicaid, the program is a voluntary federal-state partnership. The first states to implement Medicaid started in 1966, and nearly all states implemented the program by 1970. This created variation in age at first exposure which depends only on the location and date of a child's birth. Because no state repealed Medicaid once adopted, the timing of first exposure is perfectly correlated with the amount of exposure over a given age-range, assuming negligible interstate migration. Medicaid's adoption is a useful tool for understanding the program's long-term benefits because it targeted a group of very low- 
income families that had few health insurance alternatives, and because it occurred sufficiently long ago that we can trace its impact over more than four decades.

Prior to Medicaid's passage into federal law in 1965, cash-assistance recipients received medical benefits through vendor payment programs that varied substantially by eligibility category and state. When a state provided any services at all, the benefits were modest. In only nine states did per beneficiary spending reach at least half the level of age-and-sex adjusted perperson medical spending in the general population (U.S. House Committee on Ways and Means, 1961).

The goal of the Medicaid program was to increase access to care and ultimately improve the health of low income families. It was a large, though incremental change to the existing system (Stevens and Stevens, 1974). Medicaid continued the existing practice of delivering medical care by paying private providers directly (at levels below private market rates) through joint state and federal financing. The key changes included A) a requirement that states cover all people on public assistance; B) a mandate that all states cover a set of essential benefits that included physician visits, hospital stays, lab and x-ray services with no cost-sharing and an extended set of services at the states' option; C) a consolidation of the existing public assistance medical care programs; D) increased federal participation in financing; and E) an extension of coverage to the medically needy at the states' option (Holahan, 1975). Medicaid covered a set of basic services for both pregnant women and children that could have improved both short and long-run health. Such services include vaccinations, antibiotic treatment of conditions such as pneumonia, hospital services, neonatal intensive care, nutritional treatments for disorders such as anemia, and medical supervision during pregnancy.

Adoption of Medicaid by the states was voluntary, but all federal financing through the pre-existing welfare medicine programs ended on December 31, 1969. The first allowable date to begin a program was January 1, 1966. Twenty-six states had adopted programs by the end of 1966 and by 1970 all states, save Alaska (1972) and Arizona (1982), had a program.

The largest group of non-elderly Medicaid participants was participants in Aid to Families with Dependent Children (AFDC) who were mandated to be automatically enrolled in Medicaid. AFDC was provided primarily to low income unmarried mothers and their children. For a family of 3 in 1970 the needs standard ranged from \$149/month in Arkansas (58\% of poverty) to $\$ 351 /$ month in California (136\% of poverty) (U.S. House Committee on Ways and 
Means, 1996). Strict eligibility rules limited the AFDC program to a relatively small fraction of the population. In 1970, there were approximately 8.5 million recipients, comprising roughly $4 \%$ of the general population or $36 \%$ of people in families with less than $\$ 3,000$ in family income. Despite the close link between Medicaid and AFDC at Medicaid's inception, it would be an overstatement to say that Medicaid was exclusively a benefit extended to single parent families on welfare. Twenty-nine states had medically needy programs, 30 states covered income-eligible women pregnant with their first child, and 18 states covered needy children under the age of 21 , regardless of their categorical AFDC eligibility (Davis and Schoen, 1978; Foltz, 1975).

Few empirical studies examine Medicaid's introduction even though it was one of the largest public health investments for low-income populations in U.S. history. Decker and Gruber (1993) using a difference-in-difference design, find that Medicaid's introduction reduced the incidence of low birth weight in the low-income population (less than $\$ 2,000$, nominal dollars) by a striking $60 \% .^{6}$ Using a different study deign, Goodman-Bacon (2015) finds that the introduction of Medicaid reduced mortality for non-white children under age 15 by 24 percent for groups that participated in the program. Both papers support the idea that the introduction of Medicaid improved children's health in ways that could be important over the long-term. Goodman-Bacon's results are particularly important because they suggest that Medicaid increased the probability of surviving past childhood. We assume that the children who survived as a result of Medicaid were in worse health than the general population and therefore our results represent a conservative estimate of Medicaid's effect.

Historical data from the National Health Interview Surveys suggest that Medicaid's introduction had significant effects on health services use for children. In Figure 1 we describe the unadjusted differences in the probability of any overnight hospital stay and any annual physician visit for low-income children, who were targeted by Medicaid, and their moderate income counterparts who were not. In 1964, just prior to Medicaid's introduction, low income children were 0.8 percentage points less likely to have any hospital visits and nearly 20 percentage points less likely to have had a physician visit compared to moderate income children. By 1974, after all states but Arizona had adopted Medicaid, low-income children were using more hospital services compared to moderate income children and the physician visit

\footnotetext{
${ }^{6}$ The authors note that their estimates have serious limitations because their data excluded a large share of the potentially eligible population.
} 
difference had been cut by nearly $80 \%$ of its base level. These raw data suggest that Medicaid had a large effect on access to health services for low income children. We return to this issue in Section 5 where we conduct a more detailed analysis of hospital stays. 


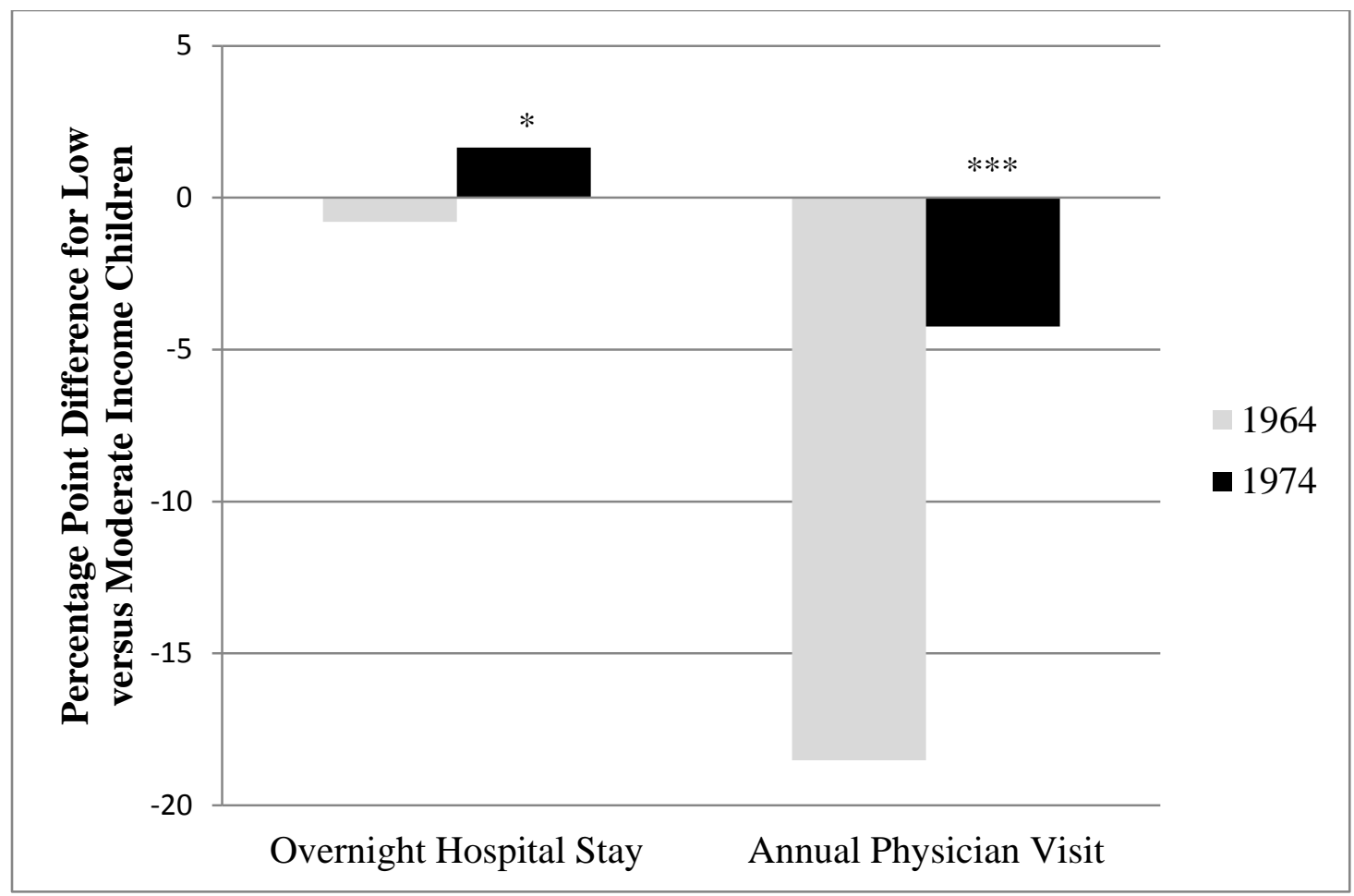

Figure 1. Percentage Point Differences In Utilization Outcomes for Low and Moderate Income Children ages 0-5, 1964 and 1974

Notes: Source: 1964 and 1974 National Health Interview Survey. Low income is defined as family income less than $\$ 3,000$ in 1974 dollars and moderate income is between $\$ 5,000$ and $\$ 10,000$. The statistical significance of the difference in differences between years is denoted by $* \mathrm{p}<0.1 ; * * \mathrm{p}<0.05 ; * * * \mathrm{p}<0.01$.

Figure 2 describes Medicaid's rollout across the states, indexed by quarter. The dates in Figure 2 represent implementation dates and are used throughout this paper to represent Medicaid adoption timing. ${ }^{7}$ States likely differed in the exact timing of beneficiary notification. For example, New York's program was implemented in May of 1966 and the state's 575,000 AFDC beneficiaries were automatically enrolled at that time. However, identification cards were not mailed until October 1966, the same month the state began accepting applications from nonwelfare eligibles (New York Times, 1966a,b). Unfortunately, we do not observe notification

\footnotetext{
${ }^{7}$ Implementation dates were obtained from Characteristics of State Medical Assistance Programs under Title XIX of the Social Security Act (U.S. Department of Health, Education, and Welfare 1970). This list was cross-checked and supplemented by a list obtained from the Office of the Historian at the Social Security Administration.
} 
dates for the rest of the states and we know of no source that describes public knowledge of the program. Therefore, we rely on implementation dates which are a policy relevant and measurable marker of the presence of Medicaid.

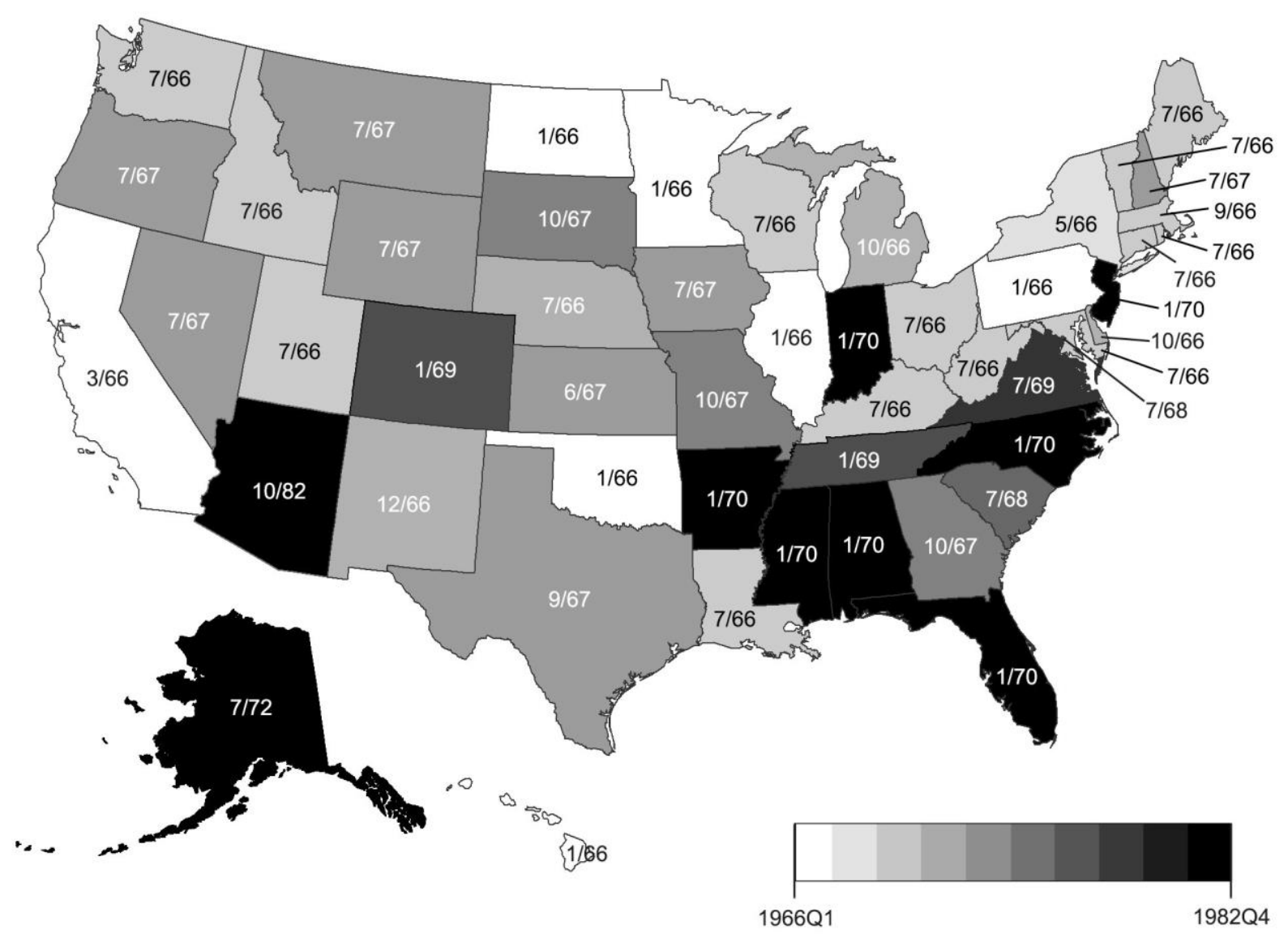

Figure 2. Medicaid Adoption by Quarter

Notes: Adoption dates come from the Department of Health Education and Welfare (1970) \& Social Security Administration (2013). The map is shaded relative to the quarter of adoption and states are labeled with the month and year of adoption.

The general pattern in Figure 2 corroborates historical reports that states with relatively generous existing welfare medicine programs (primarily concentrated in the Northeast) had incentives to adopt programs quickly so that expenditures could be shifted to the federal budget (Stevens and Stevens, 1974). In states with less generous programs (particularly in the South) 
Medicaid represented a new expenditure and adoption tended to occur later. However, there are clear breaks in the general geographic pattern-e.g. New Jersey adopted relatively later than its neighbors and Louisiana and Georgia adopted relatively sooner than the rest of the Deep South.

An obvious concern with Medicaid adoption timing is its potential correlation with other factors that also affected the outcomes of interest. Strumpf (2011) reports that a series of preMedicaid state-level factors (i.e. local welfare spending, age distribution, etc.) were not correlated with the timing of Medicaid's adoption, but her analysis was only based on 14 state observations. Other research suggests that the timing of Medicaid's adoption was correlated with other meaningful changes. Finkelstein (2007) suggests that the timing of Medicaid adoption was spuriously correlated with changes in hospital capacity. We use two methods to address potential confounding with provider supply. First, our models directly control for county-by-year per capita hospital supply (using the same data described in Finkelstein, 2007) and county-by-year per capita physician supply (obtained from the Area Health Resources File). Second, changes in hospital capacity would not only affect the population eligible for Medicaid. Moderate income families also experienced substantial access barriers, but were not eligible for Medicaid (Davis and Schoen 1978). This suggests a useful falsification exercise: Medicaid's adoption ought to have no impact on children raised in moderate income families who experienced similar resource constraints, but were not income eligible for the program.

Goodman-Bacon (2015) suggests that the timing of Medicaid adoption was correlated with pre-treatment declines in non-white infant mortality (he could not reject the equality of pretrends for white infants born in early versus late adopting states). However, he finds that pretreatment changes in infant mortality, child poverty rates, single-parent households, and AFDC benefit standards, were not correlated with relative state-level participation rates for AFDC- the principal pathway through which people gained access to Medicaid. In similar analyses we found that state level AFDC rates and growth trends were poor predictors of Medicaid adoption timing (Boudreaux 2014). State level differences in the intensity of exposure to Medicaid, via AFDC rules, provides a useful additional source of variation to further isolate the impact of Medicaid. We leverage that variation in triple difference comparisons in Section 4.2. The models estimate the relative impact of Medicaid exposure for groups with varying predicted probabilities of AFDC participation. These predicted probabilities are estimated using arguably exogenous 
characteristics used in eligibility determination (see below) including relative state level AFDC eligibility thresholds in 1970 .

Our empirical strategy, described in more detail below, relies on variation from withinstate changes in Medicaid availability over time, cross-state differences in Medicaid availability at a point in time, and between-group differences in the propensity to participate in Medicaid. Using fixed effects, we control for any time-invariant state level factors or any unique cohort factors that could be correlated with the timing of adoption and the outcomes of interest. We also include a detailed set of geography-by-year controls and find that our results are robust to statespecific linear time trends.

\section{Methods}

\subsection{Data and Descriptive Statistics}

To examine Medicaid's long-term impact we use microdata from the 1968-2009 Panel Study of Income Dynamics (PSID) (Panel Study of Income Dynamics, 2012). The PSID began in 1968 and annually (biennially as of 1997) follows participants and their descendants. The original sample consisted of about 5,000 households, including an oversample of low-income families that allows us to focus specifically on groups that had a high probability of participating in Medicaid. The PSID maintains extraordinarily high wave-to-wave response rates ( 98\%), but given the length of the panel these small losses result in appreciable attrition. Attrition bias due to earnings, education, marriage and welfare receipt appears minimal (Gouskova et al., 2008; Fitzgerald et al., 1998).

We restrict the analytic sample to cohorts born between 1955 and 1980 . This provides 6 cohorts that had no exposure to Medicaid prior to age 6 (we define early childhood as ending in the month of the $6^{\text {th }}$ birthday), 10 cohorts that were exposed starting at conception, and 10 that were exposed starting at some point in the early childhood period. Our definition of the early childhood period, encompassing the ages 0-5, has been used in previous studies of child development (e.g., Duncan et al., 1994; HSA, 2014), and covers the period prior to typical entrance into school. ${ }^{8} \mathrm{We}$ include only observations that are observed when they are household

\footnotetext{
${ }^{8}$ Our results are robust to defining the early childhood period from conception to the $5^{\text {th }}$ birth day and the appendix provides additional analyses of heterogeneous effect by the timing of first exposure.
} 
heads or spouses and are age 25 and over. We restrict the sample to age 25 and over to ensure completed education. Thus, the sample of interest includes only adults, but by utilizing the longitudinal nature of the PSID in combination with retrospectively reported variables, we observe their childhood characteristics. We drop observations whose first PSID interview occurred after age 13 because we cannot determine their early life covariates with confidence. We also remove children born in Arizona because its Medicaid start time is a clear outlier. ${ }^{9}$

State of residence is available on the public use PSID. This allows us to identify the state of birth for each observation. For cohorts born prior to 1968 we infer state of birth from the family's residence in 1968 (the first year of interview). To reduce measurement error in state of birth we restrict the sample born prior to 1968 to those that did not move between birth and the 1968 interview, identified using retrospective mobility questions. ${ }^{10}$ Using state of birth we assign Medicaid adoption dates (measured to the year and month). The PSID also ascertains month of birth. Similar to HSA and in the spirit of other work (e.g. Bleakley 2007), we measure Medicaid availability as the fraction of months exposed during early childhood. The early childhood period spans from the approximate month of conception to the month of the $6^{\text {th }}$ birth day for a total of 81 possible months of exposure. To account for potential non-random migration the exposure variable is calculated based on state of birth. ${ }^{11}$ Because all states eventually adopted a program and none repealed after implementation, a higher value for the Medicaid exposure measure represents having been first exposed to Medicaid at a relatively earlier point in life.

Figure 3 plots the number of months exposed to Medicaid by birth cohort, as observed in the data. Beginning in the 1960 birth cohort, the average level of exposure increases by 5-10 months a year. By the 1972 birth cohort all sample members were exposed to a Medicaid program starting at conception. The error bars mark 1 standard deviation above and below the mean to provide a sense of the intra-cohort variability in the data that is driven by state and month of birth. The graph demonstrates substantial variability in months of exposure during the

\footnotetext{
${ }^{9}$ Less than $1 \%$ of the analytical sample was born in Arizona. Thus, this exclusion has a negligible effect on the results.

${ }^{10}$ In practice this step removes a very small fraction of the sample: 179 unique persons or $1.4 \%$ of people born prior to the 1968 interview.

${ }^{11}$ A weighted $6.1 \%$ of our analytical sample moved states during the early childhood period. This is less than Census Bureau's estimate of interstate migration for the population 5 years and older between 1965-1970 (8.6\%). All results presented here are qualitatively robust to the removal of subjects that migrated states in the early childhood period. However, we prefer including these cases and calculating their exposure from their birth state of residence because it gives an intent-to-treatment estimate that is more realistic of the alternative policy choices. See the online technical appendix for the migration robustness results.
} 
early childhood period. In the 1962 birth cohort, exposure to Medicaid averaged roughly 10 months and in the 1970 cohort averaged just less than 80 months. The staggered introduction of Medicaid across states also created within cohort variation. For example, roughly $20 \%$ of the 1965 cohort was exposed to Medicaid for less than 20 months in early childhood, 47\% were exposed for 20 to 60 months and 33\% were exposed for longer than 60 months.

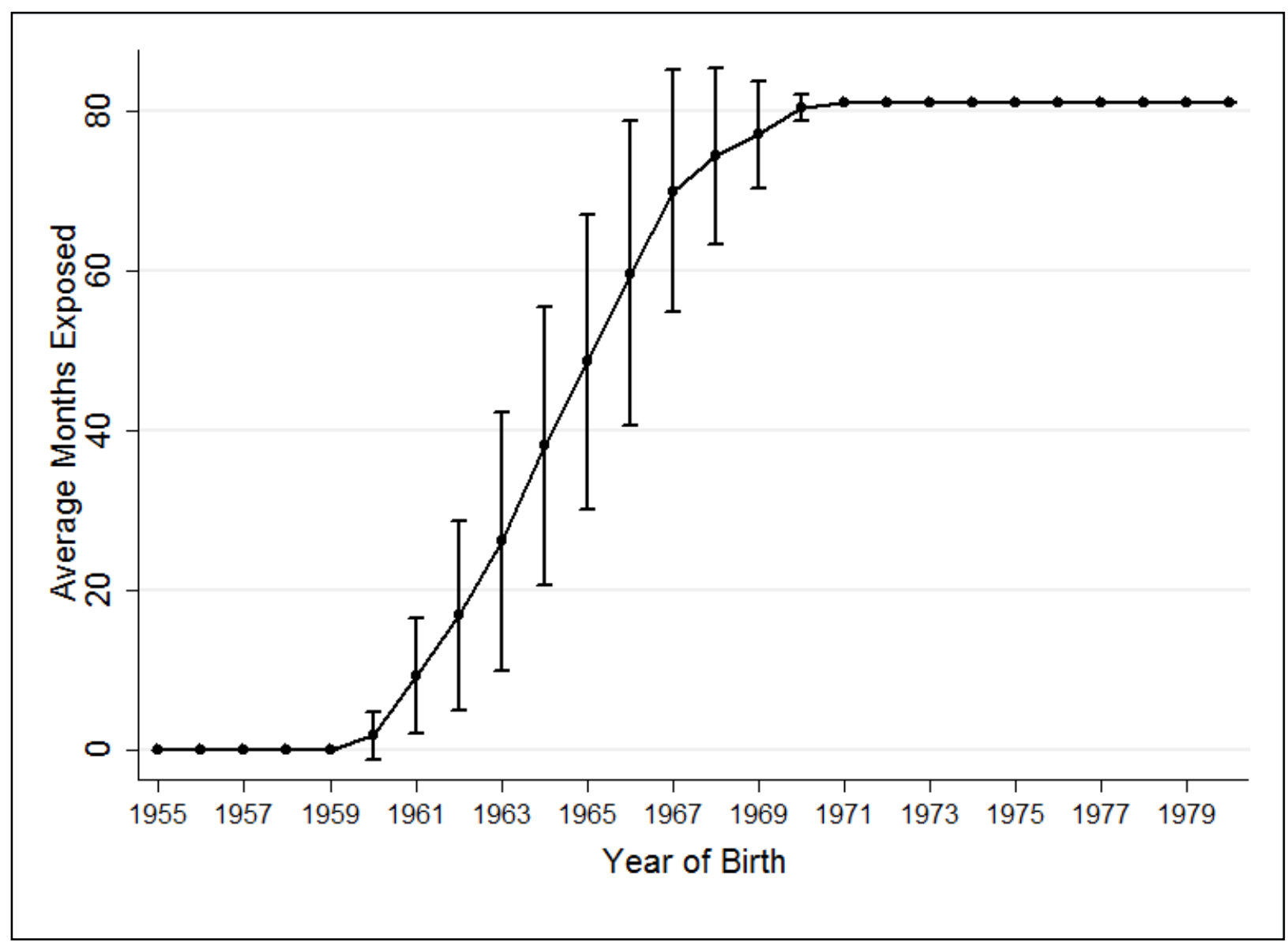

Figure 3: Number of Months Exposed to Medicaid during Early Childhood, by Birth Cohort

Notes: Source: The 1955-1980 birth cohorts from the 1968-2009 PSID (person level observations). Error bars represent 1 standard deviation above (below) the mean and are not constrained by 81 months.

Since its inception, the PSID has collected extensive data on socioeconomic and demographic characteristics. The childhood characteristics we consider include the education of 
family head, poverty level, and marital status of the mother at birth. We also use the socioeconomic data measured during adulthood to observe a set of economic outcomes including years of completed education (top coded at 17 years), the continuous ratio of family income to the federal poverty line and family wealth measured in 2000 year dollars. ${ }^{12}$ To handle the skewed distribution of family wealth which includes zero and negative values we measure family wealth by categorizing the sample distribution into deciles. The average level of wealth in the lowest decile is $\$-33,172, \$ 17,454$ in the fifth decile and $\$ 1,074,344$ in the tenth decile.

In 1999, respondents began providing detailed information on specific health conditions including hypertension, heart disease, heart attack, and diabetes. The PSID questionnaire ascertains whether the head or spouse was ever diagnosed with a condition and the age at first diagnosis. The survey also collects measures of self-reported height and weight that we use to construct body mass index (BMI) and an indicator of obesity (BMI $\geq 30)$. Previous work suggests that these health outcomes are sensitive to early life conditions (Gluckman, et al., 2007; Currie and Almond, 2011; Montez and Hayward, 2011). Specifically, life-long disease risk is partially determined by exposures in the prenatal environment and/or through childhood health conditions that can lead to chronic inflammation responses. Medicaid could intervene in these processes by improving the prenatal environment through the provision of prenatal care or by improving the general health of the mother prior to conception. In addition Medicaid could prevent childhood illness through preventative care (e.g. vaccinations) or by increasing access to effective treatments of childhood disease when it occurs, thereby reducing the severity of long-run sequelae. Additionally, Medicaid could free-up family income to be spent on nutrition or to improve a family's physical environment The health data are coded to indicate undesirable outcomes (i.e. ever being diagnosed with heart disease, etc.). Heart disease and heart attack are combined to accommodate their low prevalence. The diabetes indicator is set such that only cases that report an age of onset greater than or equal to 18 are considered to have the condition. We focus on adult onset diabetes because diabetes is a relatively common childhood condition and we want to ensure that our estimates reflect Medicaid's impact on adult health and not Medicaid's impact on the detection of childhood conditions.

We summarize the individual health condition and economic outcomes by creating a chronic condition index variable and an economic index variable. By summarizing the outcome

\footnotetext{
${ }^{12}$ Poverty is defined using the federal poverty levels suggested by Grieger et al. 2007.
} 
variables we gain statistical precision and reduce problems associated with multiple-comparisons (Andersen, 2008). Following previous authors (Andersen, 2008; Hoynes, et al., 2014), the indexes are constructed as the equally-weighted average across each variable's z-score. The condition index includes high blood pressure, heart disease/heart attack, adult onset diabetes, and obesity and is constructed such that increasing values indicate worse health (i.e. increasing prevalence of conditions). The economic index, including years of education, poverty level, and decile of family wealth, is constructed such that increasing values indicate a greater level of economic resources. The distribution of the chronic condition index gives some intuitive meaning to the health index: the average health index value for those without any condition is 0.4 and ranges to 3.1 for those with 4 conditions. A 1 standard deviation increase in the condition index is associated with an increase in the number of chronic conditions by 1.4 , on average.

Table 1 presents descriptive statistics from the analytical sample which is constrained to the 1999-2009 waves and consists of adults age 25 and above. The data are organized into person-year observations. There are 17,125 person-year observations with non-missing condition index values, representing 3,830 unique individuals. On average each person has a non-missing condition index for 4.6 years (out of a possible of 6 ). ${ }^{13}$ The average exposure to Medicaid, measured as the fraction of time exposed in early childhood, is $0.53 .47 \%$ of the sample is male and $82 \%$ is white. Roughly $19 \%$ had family incomes below $150 \%$ of the poverty line during early childhood and $37 \%$ lived in moderate income families with family income between 175 and $300 \%$ of poverty. In adulthood, $9 \%$ of the sample reported being in fair health or worse; $14 \%$ reported ever being diagnosed with hypertension; 3\% with heart disease or heart attack; and 25\% met the threshold for obesity. The weighted mean of the condition index was -0.05 (the unweighted mean was -0.001). The average number of years of education was 13.6, the average income to poverty ratio was 5.3 and the average wealth decile value was 6.1 . The weighted mean of the economic index was 0.16 (the unweighted mean was -0.003). In the appendix we examine how these characteristics differ between early and late adopting states. As expected, the population in later adopting states was more likely to be low-income and to be exposed to lower levels of public assistance spending in early childhood.

\footnotetext{
${ }^{13}$ The average condition index is statistically indistinguishable for cases that have complete data versus cases that are have at least one year of data, but are missing 1 or more years (difference $=.01 ; \mathrm{p}=0.38$ ). The same holds for the Medicaid exposure variable and the economic index. Therefore, we assume that item missingness occurs completely at random.
} 


\section{Medicaid Exposure}

Fraction of Months Exposed in Early Childhood

$$
\text { Mean }
$$

SD

Min $\quad$ Max

Basic Demographics

Gender (Male)

$\begin{array}{rrrr}0.53 & 0.45 & 0 & 1 \\ 0.47 & 0.50 & 0 & 1 \\ 0.82 & 0.38 & 0 & 1 \\ 38.24 & 7.27 & 25 & 54 \\ 0.69 & 0.46 & 0 & 1\end{array}$

Race (White)

Age

Married

$\begin{array}{llll}0.19 & 0.39 & 0 & 1 \\ 0.37 & 0.48 & 0 & 1 \\ 0.30 & 0.46 & 0 & 1\end{array}$

\section{Health Outcomes}

Health Index

Fair Health or worse

$\begin{array}{ll}-0.05 & 0.55\end{array}$

0.09

0.29

$-0.4$

0.14

0.35

0.03

0.16

0.02

0.15

0.25

0.44

$\begin{array}{rrrr}0.16 & 0.78 & -2.8 & 28 \\ 13.59 & 2.08 & 1 & 17 \\ 5.32 & 8.27 & 0 & 570.2 \\ 6.11 & 2.94 & 1 & 10\end{array}$

\section{Selected Area-by-Year Controls}

Average per capita Public Assistance Spending, Age 0-5 (2000 yr \$)

Average \# Hospitals per 100,000 people, Age 0-5

Average \# Physicians per 100,000 people, Age 0-5

$\begin{array}{rrrr}3.45 & 4.40 & 0 & 43.6 \\ 124.61 & 82.30 & 0 & 829.8 \\ 0.47 & 0.45 & 0 & 1 \\ 0.13 & 0.32 & 0 & 1 \\ 0.47 & 0.45 & 0 & 1\end{array}$

\section{Sample Size}

Person-Year Observations

17,125

Unique Person Observations

Years Observed

4.6

Source: 1968-2009 PSID. See text for a description of the analytical sample. All estimates are weighted. Sample size describes observations with non-missing condition index values which applies only to the 1999-2009 waves. 


\subsection{Empirical Strategy}

To identify the effect of Medicaid's long term impact we regress a given health or economic outcome on the fraction of months a person was exposed to the Medicaid program during early childhood. The model takes the form described in equation 1 :

$$
y_{\text {inst }}=\lambda M C A I D S H A R E_{s t}+\beta X_{\text {inst }}+\phi Z_{s t}+\rho_{n}+\delta_{t}+\gamma_{s}+e_{\text {inst }}
$$

where $y_{\text {inst }}$ is a health or economic outcome, for person $i$ at adult interview year $n$, born in state $s$ and year $t$. MCAIDSHARE is the continuous measure of Medicaid availability in the early childhood period and $\lambda$ measures the effect of moving from no exposure to full exposure (i.e. MCAIDSHARE increasing from 0 to 1). Because the Medicaid programs were never repealed, every person in the 1955-1980 cohorts was exposed to Medicaid at some point in their lives (albeit perhaps not until after the early childhood period). As a result of this feature of the policy experiment, the coefficient on our exposure measure captures the effect of a marginal increase in exposure earlier in life. ${ }^{14}$ It includes the effects of both duration and timing.

$X_{\text {inst }}$ is a set of individual level controls, including gender, race (white vs. other), a quadratic in age, and marital status. ${ }^{15}$ These variables control for compositional differences correlated with Medicaid exposure and will improve the precision of the model. $Z_{s t}$ is a set of geography-by-year controls that we describe in more detail below. The model includes interview year fixed effects $\left(\rho_{n}\right)$, year of birth fixed effects $\left(\delta_{t}\right)$ and state of birth fixed effects $\left(\gamma_{s}\right)$. These hold constant any stable, but unobserved period or state effect. In the appendix we demonstrate that our results are robust to removing the demographic and area-by-year controls and to including state specific trends in birth cohort. In all analyses the PSID weights are used to adjust for the differences in the initial probability of selection and attrition over time (Gouskova et al., 2008). Standard errors are clustered on state of birth (Bertrand et al., 2004; Cameron and Miller, 2015) and in the appendix we show our inferences are robust to bootstrap estimation. Models

\footnotetext{
${ }^{14}$ Take, for example, a person with 45 months of exposure versus a person with 81 months of exposure. The former person's exposure to Medicaid began on their third birthday (assuming 9 months of gestation) whereas the later was exposed since conception.

${ }^{15}$ We were concerned about the collinearity of age given the presence of interview year and birth year fixed effects. However, results are robust to measuring age in categories or removing age entirely from the model. Results are also robust to excluding current marital status which is potentially endogenous.
} 
using continuous outcomes are estimated with OLS and regressions of binary outcomes use linear probability models.

As discussed above, the eligibility criteria for Medicaid provides an additional dimension of variation to help identify the effect of exposure to Medicaid in early childhood. We estimate equation (1) on sub-groups that vary in their propensity to be eligible for Medicaid in early childhood. Finding effects in groups with relatively high Medicaid participation and null results in non-targeted placebo groups with low participation will support the assumption that adoption timing was not correlated with other meaningful secular trends, such as medical technology diffusion or changes in social and economic environments that affected the entire population. The "high impact" subgroup is composed of adults raised in families that had incomes less than $150 \%$ of the poverty level, on average, during early childhood. The low impact "placebo" subgroup is composed of adults raised in moderate income families that had incomes between $175-300 \%$ of poverty. ${ }^{16} \mathrm{We}$ chose to focus on a moderate income group as the placebo comparison because that group experienced barriers to health care access at the time of Medicaid's introduction, but were not eligible for the program (Davis and Schoen, 1978). ${ }^{17}$ In practice, the PSID does not include observations for each of these sub-groups in every state. Our low-income sample consists of observations from 36 states and the moderate income group includes observations from 39 states. The appendix shows that the sub-group samples have Medicaid adoption distributions that are nearly identical to Figure 3 and that constraining both sub-groups to be a balanced state panel leads to nearly identical results as those presented here.

The PSID has also tracked AFDC participation since 1968, but we chose not to examine AFDC participants directly because AFDC participation decisions are clearly endogenous and because the increase in AFDC participation after the introduction of Medicaid (Decker and Selk, 2011) could contribute to compositional biases. In section 4.2 we examine a triple-difference specification that approximates the effect of the treatment-on-the-treated without relying directly on indicators of AFDC participation. This approach also utilizes more sources of variation in the

\footnotetext{
${ }^{16} 150 \%$ of the federal poverty line roughly translates to the un-weighted average of "gross" income eligibility limits for a 3 person family that prevailed across the states in 1970. Thus, this group approximates the group of income eligible. The early childhood period for the purpose of defining the low income group runs from conception through age 5 for those conceived in 1968 or later and 1968-1972 for those conceived prior to 1968. Forcing all cohorts to have the 1968-1972 childhood period has no qualitative effect on the results.

${ }^{17}$ In the appendix we also show placebo results for children born in high-income families. Those results generally mirror results for moderate income families however the treatment variable showed a stronger and negative correlation with the economic index.
} 
likelihood of Medicaid participation compared to income stratification alone. Consistent results across models will provide support for our findings.

It is possible that some unobserved factor that improved the life chances of low SES children, but not higher SES children, is correlated with Medicaid adoption time. The period of Medicaid's implementation was characterized by an explosion in public assistance programs. The Food Stamp Program, Head Start, and Community Health Centers were all rolling out around the same time as Medicaid's introduction. If these programs have long-term impacts that are concentrated in the high impact subgroups then the effect of Medicaid could be overstated and null results in the high SES groups would not be as informative.

To account for that possibility we include a detailed set of contextual controls that are linked by state or county of birth. ${ }^{18}$ At the county level we observe the number of per capita doctors and short-term general hospitals, real per capita spending on public assistance (e.g. AFDC, general assistance, food stamps, and SSI), and whether the county of birth had one of several War on Poverty era programs that was implemented at the county level (Food Stamps, Head Start, Community Health Centers, Family Planning, Maternal and Child Health grants, other health related programming, and job training grants). ${ }^{19}$ The health care market and public expenditure data are measured as the average level in the early childhood period and the program variables are specified as the fraction of months exposed during early childhood (the exception is family planning which is specified as an indicator if a program existed at the time of conception). At the state level we observe unemployment, real AFDC benefit standards and per capita AFDC caseloads, all measured as the average in the early childhood period. We also include an indicator if the adult was conceived in a state and year with legalized abortion. County-level covariate data were not available for Alaska, Hawaii, the District of Columbia, and Virginia, and that portion of the sample was dropped $(n=3,068 ; 4.4 \%$ of the total sample). All models control for the full set of contextual controls $\left(Z_{s t}\right)$.

\footnotetext{
${ }^{18}$ County of residence is a restricted use variable which we obtained through special arrangement with the University of Michigan.

${ }^{19}$ We are indebted to Doug Almond, Hillary Hoynes, Amy Finkelstein, Martha Bailey and Andrew GoodmanBacon for providing and assisting us with these contextual data. The online appendix provides a fuller description of each source.
} 


\section{Main Results}

In Table 2 we report the coefficients for the Medicaid exposure variable in the health outcome models for each of the subgroups described above. ${ }^{20}$ Each set of results come from models that control for the full set of demographic controls, area-by-year controls, and fixed effects. The top panel includes results for the condition index and the bottom panel describes results for self-reported health status and the 4 chronic condition indicators that constitute the index (ever being told that you have high blood pressure, heart disease or heart attack, diabetes after the age of 18 , and meeting the BMI threshold for obesity).

Table 2. The Impact of Exposure to Medicaid in Early Childhood on Adult Health, by Income

\begin{tabular}{l|rr|rr}
\hline & \multicolumn{3}{|c|}{$\begin{array}{c}\text { Low Income } \\
(<\mathbf{1 5 0 \%} \text { FPL) }\end{array}$} & \multicolumn{3}{c}{$\begin{array}{c}\text { Moderate Income } \\
(\mathbf{1 7 5 - 3 0 0 \%} \text { FPL) }\end{array}$} \\
\hline & Coefficient & SE & Coefficient & SE \\
Chronic Condition Index & $-0.35^{* *}$ & 0.17 & -0.07 & 0.14 \\
Sample Size & 5,607 & & 5,330 & \\
Mean of Y & 0.08 & -0.06 & \\
$\mathrm{R}^{2}$ & 0.18 & & 0.11 & \\
\hline \hline Fair Health or Worse & -0.01 & 0.13 & -0.01 & 0.06 \\
High Blood Pressure & $-0.22^{* *}$ & 0.10 & -0.12 & 0.10 \\
Heart Disease/Heart Attack & -0.02 & 0.05 & -0.05 & 0.05 \\
Adult Onset Diabetes & -0.04 & 0.05 & 0.04 & 0.04 \\
Obesity (BMI $\geq 30)$ & -0.22 & 0.16 & -0.04 & 0.17 \\
\hline
\end{tabular}

Source: PSID 1968-2009. All parameters are from separate regressions. Models include a quadratic in age, gender, race, marital status, the full set of contextual controls described in the text, interview year fixed effects, state of birth fixed effects, and year of birth fixed effects. See text for an explanation of the analytical sample, the income groups, and construction of the chronic condition index. All estimates are weighted and standard errors are clustered on state of birth. $* \mathrm{p}<0.1 ; * * \mathrm{p}<0.05 ; * * * \mathrm{p}<0.01$

In the low income group, the results imply that the effect of moving from no exposure to full exposure is a 0.35 standard deviation reduction in the condition index (indicating improved health). The estimate is statistically significant at the 5\% level. Looking at the specific health measures, the results for the indicator of fair or poor health are small and quite imprecise. The

\footnotetext{
${ }^{20}$ The full set of results is available in the appendix.
} 
Medicaid exposure coefficients for specific condition indicators are all negative as expected. However, we are only able to detect a significant effect to high blood pressure. The coefficient in the low income group implies that that full exposure to Medicaid in early childhood, versus its absence, is associated with a 22 percentage point decline in prevalence of high blood pressure, significant at the $5 \%$ level.

The right hand panel of Table 2 describes model results in the moderate income (placebo) sample. For all outcomes considered, the coefficients are small and not statistically significant. For example, the coefficient for the condition index is a non-significant -0.07 . The pattern of results in the placebo groups suggest that the health impacts observed in the high impact group are not being driven by unmeasured underlying trends correlated with adoption timing.

Table 3 presents outcomes for the economic outcomes. The table is organized in the same fashion as Table 2. The outcomes include the economic index, years of education, the ratio of family income to the poverty line, and the decile of family wealth. Regardless of the impact group or the outcome measure there is no statistically conclusive evidence that exposure to Medicaid in childhood improves adult economic status. For example, the coefficient for the economic index in the low income group is negative (suggesting worse economic outcomes), but not significant. However, the standard errors are large and we cannot exclude a large range of effects. In the placebo group the effect of Medicaid's introduction on the economic index is positive and non-significant. In the case of family wealth the coefficient in the placebo group is significant at the $10 \%$ level $(\mathrm{p}=0.08)$. 
Table 3. The Impact of Exposure to Medicaid in Early Childhood on Adult Economic Attainment, by Income

\begin{tabular}{l|rr|rr}
\hline & \multicolumn{2}{|c|}{$\begin{array}{c}\text { Low Income } \\
\text { (<150\% FPL) }\end{array}$} & \multicolumn{2}{c}{$\begin{array}{c}\text { Moderate Income } \\
\text { (175-300\% FPL) }\end{array}$} \\
\hline & Coefficient & SE & Coefficient & SE \\
Economic Index & -0.08 & 0.18 & 0.16 & 0.25 \\
Sample Size & 5,973 & & 5,739 & \\
Mean of Y & -0.31 & & 0.13 & \\
$\mathrm{R}^{2}$ & 0.30 & & 0.14 & \\
\hline \hline Years of Education & 0.10 & 0.64 & 0.87 & 0.71 \\
Continuous Income to Poverty Ratio & -1.04 & 0.84 & -2.04 & 2.20 \\
Decile of Family Wealth & -0.17 & 0.74 & $1.50 *$ & 0.83 \\
\hline
\end{tabular}

Source: PSID 1968-2009. All parameters are from separate regressions. Models include a quadratic in age, gender, race, marital status, the full set of contextual controls described in the text, interview year fixed effects, state of birth fixed effects, and year of birth fixed effects. See text for an explanation of the analytical sample, the impact groups, and construction of the SES index. All estimates are weighted and standard errors are clustered on state of birth. ${ }^{*} \mathrm{p}<0.1 ; * * \mathrm{p}<0.05 ; * * * \mathrm{p}<0.01$

\subsection{Triple Differences}

In Table 4, we focus more squarely on groups targeted by the program and formalize the comparison of treatment effects across the impact groups. To do so we use a triple difference approach run on the full sample of adults. Following the procedure suggested by Bleakley (2007), Hoynes and Schanzenbach (2009), and HSA, we modify equation (1) by interacting the Medicaid exposure variable and the predicted probability of being enrolled in AFDC in early childhood (recall that Medicaid and AFDC were mechanically linked at Medicaid's inception). AFDC participation probabilities come from the 1970 Census Long Form and are simple means defined within 48 demographic cells. The groups consist of fully cross-classified characteristics of the family head: age (3 levels), race (white/non-white), marriage (married/not-married), education (less than high school/high school or more) and whether or not the family resided in a state that had above national-average AFDC income eligibility. The participation rate groups were chosen to be characteristics that people have little control over in the short-run, but which were meaningful determinants of AFDC participation. ${ }^{21}$ The rates are merged back to the analytical sample according to each adult's family background characteristics defined at birth or

\footnotetext{
${ }^{21}$ The potential exception to this is marriage, but it provides substantial variation in AFDC participation.
} 
early life. The participation rate variable captures a higher degree of variation in Medicaid participation compared to the low and moderate income groups examined in the previous section. Particularly, the inclusion of marital status and state AFDC eligibility thresholds gives us a much clearer look at groups that were most strongly affected by Medicaid's introduction. For example, the average predicted probability of AFDC participation in the low-income group examined in the previous section was 0.1 and in the moderate income group was 0.03 . In contrast, predicted probabilities of AFDC participation range from 0.01 to 0.48 across the 48 cells. The triple difference models include the same set of demographic controls, fixed effects and area-by-year controls as equation (1), in addition to the full set of fixed effects for the 48 cells (which obviates the "main effect" of predicted participation) ${ }^{22}$ interactions of the predicted probability measure with the demographic covariates (save for race due to collinearity), and with the cohort, state of birth, and interview year fixed effects. The key interaction of Medicaid exposure*the probability of AFDC participation captures the effect of exposure to Medicaid for people with a probability of participating of 1 , compared to a probability of participating of 0 .

In the top panel of Table 4 we present results from triple difference models of the chronic condition and economic index. As expected, the main effect for Medicaid exposure for both outcomes was small and non-significant. In the condition index model, the effect of full exposure to Medicaid in early childhood for those with predicted probability of AFDC participation of 1 was -3.15 and significant at the $1 \%$ level. The coefficient suggests that for groups that were likely to have participated in Medicaid, exposure in early childhood was associated with substantial improvements in adult heath. The larger effect size, compared to results in Table 2, reflects the fact that the participation rate groups provide a more targeted look at Medicaid participants compared to the low income group. Indeed, scaling the estimates from Table 2 by the average predicted probability of AFDC participation within the low-income group suggests a similar magnitude $(-0.35 / 0.1=-3.5)$. In the economic index models the impact of Medicaid for those with predicted AFDC participation was 1.30, which suggests positive effects, but our estimates were not statistically significant. Similar to the results in Table 3, the standard errors are sufficiently imprecise that we cannot rule out meaningful impacts.

\footnotetext{
${ }^{22}$ The inclusion of the cell fixed effects implies that the variation of interest comes from the interactions between the cells.
} 
Table 4. Triple Difference Models

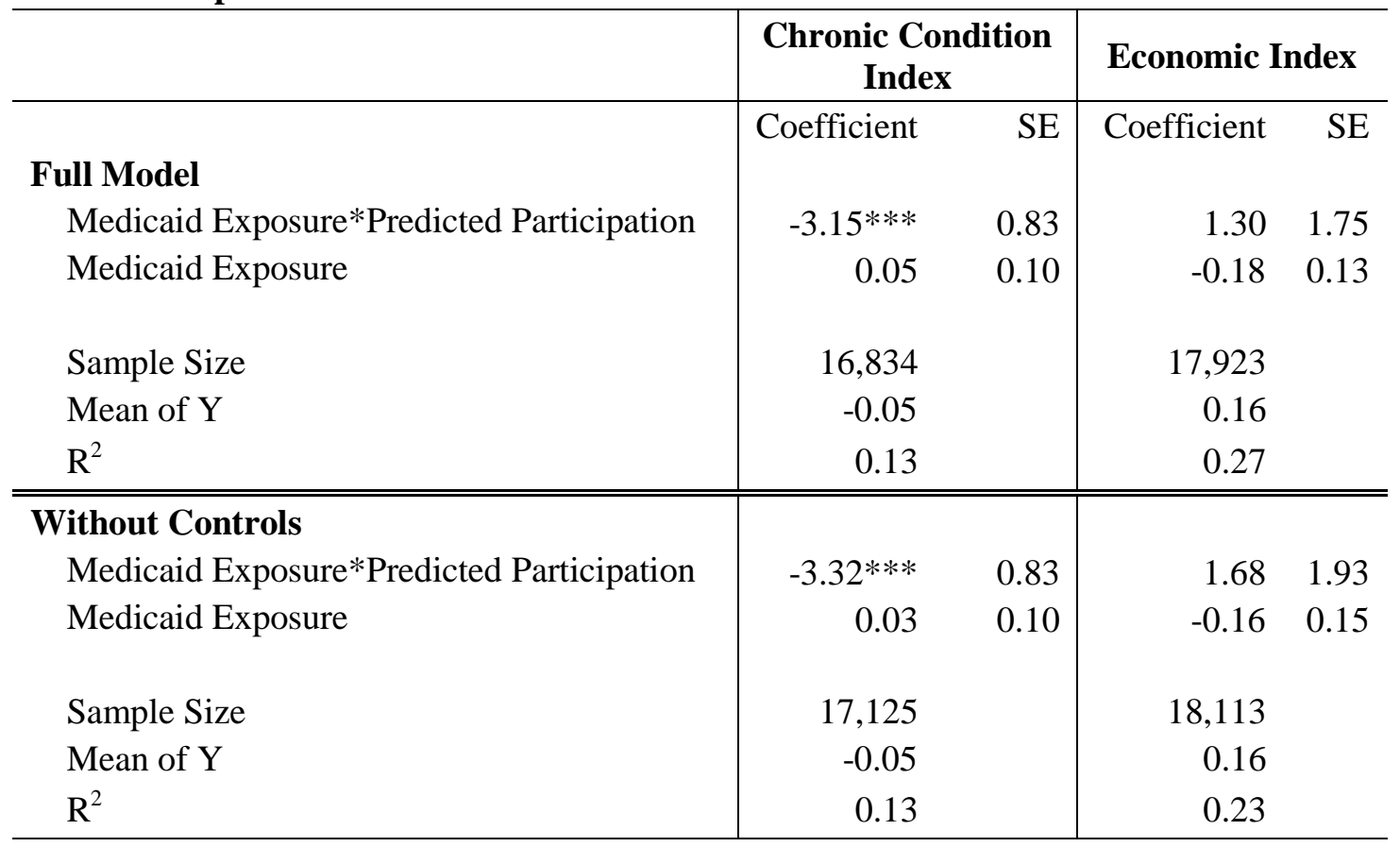

Source: PSID 1968-2009. The top panel reports results from models that include a quadratic in age, gender, marital status, race, the participation rate groups, the full set of area-by-year controls described in the text, interview year fixed effects, state of birth fixed effects, year of birth fixed effects, and interactions of the predicted participation rate and state, cohort, and interview year fixed effects. The bottom panel reports results after removing the demographic controls, and area-by-year controls. See text for an explanation of the analytical sample and construction of the outcome variables. All estimates are weighted and standard errors are clustered on state of birth. $* \mathrm{p}<0.1 ; * * \mathrm{p}<0.05 ; * * * \mathrm{p}<0.01$

In the bottom panel of Table 4 we present results from the same model after removing the demographic controls and the area-by-year controls (we duplicate this robustness test for the stratified analyses in the appendix). If the coefficients are sensitive to these exclusions it would suggest that there may be other unobserved factors that were changing according to the same pattern of Medicaid's introduction and biasing results. However, the point estimates suggest similar effects.

\subsection{Effects of Medicaid exposure at different ages}

The main focus of this study is the long-run impact of first exposure to Medicaid in the earliest years of life. However, exposure at other points in childhood could also be important. In the appendix we present results of auxiliary analyses of the relative effects of first exposure to 
Medicaid at different ages. It is important to recognize that effects might differ by age at first exposure because of relative sensitivity to the effects of Medicaid at different developmental stages (i.e. heterogeneous treatment effects by age), because more overall exposure is better, or because of age-based differences in program participation conditional on eligibility. Unfortunately, our models cannot distinguish between those channels. However, our results provide some insight into how the long-run impact of Medicaid policy might evolve across different ages at first exposure. The analyses examine the chronic condition and economic indexes and we include 10 additional cohorts so that we have a sample born from 1945-1980. Including additional cohorts improves our examination of first exposure in later years of life, but prevents us from including area-by-year controls because they are unavailable for earlier cohorts. Age at first exposure is measured by replacing the continuous fraction exposed variable in equation 1 with categorical age at first exposure, measured in 2 year bins and ranging from 5 years prior to birth to age 25 . We estimate the models for high and low impact samples defined using both income and predicted AFDC participation.

In the high impact groups (low-income and high predicted AFDC participation), exposure starting prior to birth is associated with large improvements in adult health, but additional years of exposure prior to birth are not associated with additional improvement (Appendix Figure 1). The effects attenuate for delays in exposure and become relatively stable for additional years of delay by age 8 . In the low-impact (placebo) groups (high income and low predicted AFDC), the effects were consistently near 0 until age 14 after which there was a small but stable decline in health. We found generally consistent results after pooling the impact groups (to maximize sample size) and extending the cohorts to 1935. We also estimated models using the share of months exposed during different childhood periods. The results of those models did not reveal evidence for an effect of exposure starting in later childhood or a non-linearity in exposure starting in the prenatal period. The results for the economic index are not as consistent and our models do not allow us to come to any definite conclusions about differences in age at first exposure (Appendix Figure 2).

We treat these auxiliary results with caution. We estimated wide confidence intervals for every age category. While the models suggest larger effects for exposure starting in the earliest years, which would be consistent with a sensitive developmental period, we cannot determine if the results are due to effect heterogeneity, increased duration, or participation probabilities that 
differ by age. Finally, a potential use of these graphs could be to examine our models for differential pre-trending. Doing so would require cohorts that were never exposed to Medicaid at any age, or the unrealistic assumption that exposure starting after age six had no effect on Medicaid participants. Our study design and the details of Medicaid preclude us from having truly "unexposed" cohorts - children were eligible until age 18 (and sometimes older). Adults were not as likely to be eligible, but could still obtain coverage due to childbearing, through participation in an unemployed father or medically needy program, or some other eligibility pathway.

\section{Mechanisms}

As noted in Section 2, several mechanisms could link early childhood Medicaid exposure to later life health outcomes, including improved access to health services and reductions in medical-related household financial strain. In this section we provide evidence that the introduction of Medicaid affected both of those channels.

\subsection{Effects on Health Service Use}

We use data on health service use from the 1963-1980 restricted use National Health Interview Survey (NHIS). ${ }^{23}$ We make use of harmonized variables obtained from the Integrated Health Interview Series (Minnesota Population Center and State Health Access Data Assistance Center, 2012). During this period the NHIS consistently collected data on hospitalizations, but not outpatient physician visits. Hospital utilization is an imperfect measure because it confounds access and morbidity. If Medicaid improved access to physicians the additional visits could have reduced the need for hospitalizations. However, due to the inconsistent physician visit data we are limited to focusing on the probability of any overnight hospital stay.

Our empirical strategy shares the same basic approach as our analysis of the PSID. We estimate a model that regresses a $0 / 1$ indicator of prior year overnight hospitalization on an indicator of Medicaid availability that is determined by the state and year of interview relative to the date a state adopted a program. The sample of interest includes children age 0-5 that have family incomes less than $\$ 3,000$ in 1970 dollars. We then re-estimate the models for a placebo

\footnotetext{
${ }^{23}$ For more information on the NHIS, see http://www.cdc.gov/nchs/nhis/quest_data_related_1996_prior.htm
} 
group of moderate income children with family incomes $\$ 5,000-10,000$. The model controls for simple demographics, state-by-year health market (per capital hospitals and physicians) and public policy controls (e.g. public assistance spending and Community Health Center availability, among others), state fixed effects, year fixed effects and state specific trends in survey year. The results, described in Table 5, suggest that Medicaid increased hospital utilization for low-income children by 4 percentage points. There was no impact for higher income children that had a low probability of being eligible for the program. This lends further support to our study design. ${ }^{24}$ This evidence from the NHIS suggests that the introduction of Medicaid increased use of medical services, which is one plausible channel for Medicaid's longer-term effects.

Table 5. The Impact of Medicaid's Introduction on the Probability of Any Annual Hospital Visit, by Income, Age 0-5

\begin{tabular}{l|cr|rr}
\hline & \multicolumn{2}{|c|}{ Low Income } & \multicolumn{2}{|c}{ Moderate income } \\
\hline & Coefficient & SE & Coefficient & SE \\
Medicaid & $0.04 * * *$ & 0.013 & -0.002 & 0.004 \\
Sample Size & 24,520 & & 101,793 & \\
Base Rate & 0.06 & & 0.07 & \\
\hline
\end{tabular}

Source: NHIS 1963-1980. Low-income is family income less than $\$ 3,000$ and moderate income between $\$ 5,000$ and $\$ 10,000$ (in real 1970 terms). All estimates are from separate regressions. Estimates are average marginal effects derived from logistic regression models. Models control for age (in dummies), race, gender, household head's age, household head's education, state fixed effects, year fixed effects, and state specific trends in the calendar year of survey. Medicaid is a $0 / 1$ variable that equals 1 when Medicaid exists at the beginning of the 12 month hospital visit reference period. Standard errors (SE) are based on state clusters. All estimates are weighted. $* \mathrm{p}<0.1 ; * *^{*} \mathrm{p}<0.05$; $* * * \mathrm{p}<0.01$.

\subsection{Effects on Household Medical Debt}

We were able to find one data source that included data on household financial issues around the time of Medicaid's introduction. The Survey of Consumer Finances (SCF) was conducted annually from 1946 to 1971 . The SCF collected data on household debt, income,

\footnotetext{
${ }^{24}$ We obtain qualitatively similar results when we use a measure of predicted AFDC participation in a triple difference specification. We also obtain similar results to alternative placebo groups such as low income single adult men.
} 
assets, and financial expectations, and available documentation notes that the sample is intended to be representative of the U.S. ${ }^{25}$ The SCF includes information on household composition and demographics, along with state identifiers. We focus on a single outcome from the SCF: whether the household reported having any medical debt, which was collected in 1962, 1963, 1967, 1968, and 1969. In these years, the SCF interviewed between 2,051 and 3,179 households annually. We chose to focus on household medical debt since it is the most proximate measure of financial strain that we would expect to be affected by Medicaid's introduction. This measure is also very comparable to the survey question on medical debt collected by the recent Oregon Medicaid Experiment (Finkelstein et al., 2012).

The analysis of probability of medical debt in the SCF is similar to the PSID and NHIS analyses, but is distinct in several ways. First, the unit of analysis is not the child (as in the PSID and NHIS models), but the household. Second, because the household is the unit of analysis, we are able to introduce an additional source of variation into our identification strategy: whether the household had any children under the age of 18 , since childless households would not have been eligible for Medicaid. We restrict our analysis to households where the head is age 18-59, since we wanted to avoid complications related to the introduction of Medicare in 1965 for older households while still allowing for the fact that grandparents could be affected by Medicaid if they had grandchildren in their household.

We present two models of any medical debt. The first is a triple-difference model, and looks at the effect of Medicaid's introduction, interacted with a dummy variable for low $(<\$ 3,000$ in real 1970 dollars) versus moderate $(\$ 5,000-\$ 10,000$ in real 1970 dollars $)$ family income. This model includes all households with heads age 18-59 who had at least one child under 18 in the household. Similar to the PSID and NHIS models, we include a full set of state and year fixed effects, we interact income category with the year and state dummies, and we control for household head age, race, and sex. The second model has the same specification as the first, but is restricted to households with no children under 18. This serves as a "placebo" model, since we would expect to see no effect of Medicaid's introduction on the probability of any medical debt.

The results of the SCF models are described in Table 6. The left panel displays the results of the models for families with children. The introduction of Medicaid was associated with a

\footnotetext{
${ }^{25}$ More information on the SCF is available at http://www.icpsr.umich.edu/icpsrweb/NACDA/series/00055.
} 
reduction of the probability of having any household debt of 0.11 in low-income households compared to moderate-income households. This is estimated precisely, with $\mathrm{p}=0.03$. When we look at the results for the households without children in the right panel, we see no evidence of a drop in the likelihood of having medical debt. The coefficient on the Medicaid*low-income is actually positive (0.02) although this coefficient is measured imprecisely, its $95 \%$ confidence intervals rule out a reduction in the probability of medical debt of the magnitude that we observed in the low-income sample.

Table 6. The Impact of Medicaid's Introduction on the Probability of Any Medical Debt, by Household Structure

\begin{tabular}{l|rrrr}
\hline & \multicolumn{2}{|c|}{$\begin{array}{c}\text { Households with } \\
\text { Children }\end{array}$} & \multicolumn{2}{c}{$\begin{array}{c}\text { Households without } \\
\text { Children (placebo) }\end{array}$} \\
\hline Medicaid * Low Income & Coefficient & SE & Coefficient & SE \\
Medicaid & $-0.110^{* *}$ & 0.049 & 0.02 & 0.059 \\
Low Income & 0.028 & 0.025 & $0.037 * *$ & 0.018 \\
Sample Size & $0.150 * *$ & 0.056 & $0.394 * *$ & 0.057 \\
Mean of Y & 2,555 & & 1,659 & \\
$\mathrm{R}^{2}$ & 0.238 & & 0.097 & \\
\hline
\end{tabular}

Source: Survey of Consumer Finances, 1962-1963 and 1967-1969. Models include covariates for age, sex, race, and education of household head as described in the text. Models include full set of interview year fixed effects, state fixed effects, and interactions between low-income and the state and year fixed effects. See text for an explanation of the analytical sample. Standard errors are clustered on the state. $* \mathrm{p}<0.1 ; * * \mathrm{p}<0.05 ; * * * \mathrm{p}<0.01$

\section{Discussion}

In this paper we present some of the first estimates of the long-term effects of exposure to Medicaid in early childhood. We observe the longest follow-up period of any study to date. Our identification strategy relied on Medicaid's staggered introduction across the states in combination with family-level variation in predicted propensities to participate. Depending on the specification, the effect in groups targeted by the program ranged from a 0.35 to a 3.15 
standard deviation improvement in a composite index of health conditions. We observe that exposure to the Medicaid program through the duration of early childhood, compared to its absence, improves long term health. We also present evidence that two mechanisms of these long-term effects may have been an increase in health services use and a reduction in medical debt.

The magnitude of the triple-difference result for the chronic condition index is large and two limitations should be kept in mind. It has a treatment-on-treated interpretation, comparing someone with a predicted probability of AFDC of 0 with a predicted probability of 1 . However, that is an extrapolation beyond the empirical support of the predicted participation variable, which ranges from 0.01 to 0.48 in our data. Second, while the key point estimate is significant, the confidence intervals still encompass a wide range of estimates. With these limitations in mind, it is reassuring that the stratified models (Table 2) suggest the same treatment-on-thetreated magnitude after adjusting for the average predicted participation probability in the lowincome sample (0.1).

The triple difference results can be interpreted both on the predicted probability of participation margin and the time exposed margin. Increasing the predicted participation probability by 0.1 for someone exposed to the program throughout early childhood, an analogous movement to an eligibility expansion, results in a reduction of the chronic condition index by 0.31 standard deviations. If we were to assume that years of participation have equal effect at any age, then the triple difference model suggests that an additional year of participation during early childhood, for someone likely to participate, reduces the condition index by 0.46 standard deviations (-3.15/6.75 years). Our use of composite indexes improved our statistical precision, but these results are admittedly not easy to interpret, beyond sign and significance. Another way of describing the effect of increasing the predicted participation probability by 0.1 for someone exposed to the program throughout early childhood is that it reduces the number of chronic conditions by $0.37 .^{26}$

These results are broadly consistent with other concurrently conducted work (e.g. Wherry et al. 2015; Miller and Wherry 2015). Miller and Wherry (2015) whose data and study design differ from ours, find that prenatal Medicaid coverage, on a treatment-on-the-treated basis,

\footnotetext{
${ }^{26}$ A 1 unit change in the index is associated with a 1.17 change in the sum of chronic conditions. Thus, a .31 decrease in the chronic condition index is associated with a $.31 * 1.17=0.37$ change in the sum of chronic conditions.
} 
reduces the prevalence of obesity in adulthood by 56 percentage points. In some models they estimate a 37 percent point decline in the prevalence of any chronic condition, but this result is sensitive to including state specific time trends.

The results for specific chronic conditions in Table 2 are more readily interpretable. Those results suggested that high blood pressure was particularly sensitive to early life Medicaid exposure. We estimated that full exposure to Medicaid in early life was associated with a 22 percentage point reduction in high blood pressure (the average prevalence of high blood pressure in the low-income sample is $21 \%) .{ }^{27}$ The magnitude of our blood pressure results are quite large, yet consistent with recent work examining the long-run health impacts of the Abecedarian program, a randomized intensive early childhood intervention that included health care, social and cognitive components (Campbell et al., 2014; Conti et al., 2015). Like Abecedarian, which reduced adult hypertension in men by 33-35 percentage points, Medicaid coverage in childhood appears to produce larger effects on adult blood pressure than contemporaneous behavioral interventions (Ebrahim et al., 2011). Finding the largest effects for blood pressure is not surprising given that the average age of adults in the sample was 38 .

We also examined Medicaid's long-term economic impact. However, our point-estimates were imprecisely estimated and we could not exclude a large range of potentially meaningful effect sizes on the order of those reported in Brown, Kowalski and Lurie (2014) and Cohodes et al. (2015). Our economic index combined data on years of education, family income, and family wealth. We chose to exclude measures of labor-force participation or employment because choosing to remain out of the labor force does not necessarily signal reduced economic wellbeing. However, in robustness tests we found very similar effects when including measures of employment and public program participation or removing index components such as wealth. While our results for educational outcomes are inconclusive they do align with Royer (2009) who found relatively small impacts of low birth weight on the educational outcomes of a cohort of U.S. twins, but relatively large effects on measures of adult health.

The early origins literature suggests that the earliest years of life are critical for development (Almond and Currie, 2010; Currie, 2011). Understanding the contribution of policy

\footnotetext{
${ }^{27}$ The sample average prevalence reflects the treatment effect of early childhood Medicaid exposure, and our study design precludes identifying a clean "untreated" sample to use as the basis for calculating relative effects. Another potential reference point for our results is the national prevalence of high blood pressure among poor adults, estimated to be $33 \%$ by the CDC (National Center for Health Statistics 2012).
} 
exposures at specific critical periods versus marginal increase in duration (regardless of age) is important because it informs about the implications of distributing public resources across the lifecycle. The nature of Medicaid's rollout was such that our estimates reflected the effect of additional exposure occurring earlier in life and so our findings were consistent with the idea that earlier exposure is better. We also examined age at first exposure from the prenatal period to early adulthood, the results of which suggested the largest effects for exposure starting during the prenatal period and more moderate effects lasting into later childhood. However, we are unable to determine if we were observing effect heterogeneity by age, duration of exposure effects, or differences in program participation across age.

We control for a number of relevant coincident policy changes, but like all observational studies, a limitation is the possibility that the effect of some unobserved variable was absorbed in the coefficient of interest. For instance, school and hospital desegregation created important institutional shifts around the time Medicaid was introduced and we lacked specific data on the roll-out of desegregation. Robustness to the inclusion of state-specific time trends helps to mitigate concern that bias might arise from these unobserved variables. However, to get a better sense of whether desegregation is likely to bias or otherwise explain our results, we ran a robustness check that dropped southern-born non-whites from the sample, as that is the group most likely to be affected by desegregation. Our estimates were consistent (see appendix), which increases our confidence that the results reflect the effect of the Medicaid program. Another potential area of concern is that potentially eligible beneficiaries living in late adopting states could have moved in order to gain access to Medicaid in an early adopting state, despite little evidence of Medicaid induced migration in the existing literature (Schwartz et al. 2014). However, as shown in the appendix, our results are robust to excluding adults who moved across states in their early childhood years.

The introduction of Medicaid is not perfectly generalizable to the contemporary Medicaid program and all studies of long-term effects must grapple with the problem that the exposure of interest occurred at some past date that might not generalize to the present. At its inception Medicaid targeted a lower-income group than it now covers and it is reasonable to expect that the low-income population of the late 1960's differed in substantial ways from the low-income population of today. However, the primary hypothesized mechanism linking Medicaid in childhood to later life outcomes - decreasing financial barriers to medical care that returns 
immediate health and financial gains that persist throughout the lifecycle - remains relevant. Improvements in the productivity of medical technology since Medicaid's introduction would suggest that more recent cohorts would receive more benefit from Medicaid than earlier cohorts. This paper suggests that a full accounting of Medicaid expansions and other policies that aim to increase health insurance coverage, such as the ACA, should consider downstream benefits that accrue decades in the future. 


\section{References}

Almond, D., 2006. "Is the 1918 Influenza Pandemic Over? Long-Term Effects of In Utero Influenza Exposure in the Post-1940 U.S. Population." Journal of Political Economy 114(4): $672-712$.

Almond, D., Currie, J., 2010. "Killing Me Softly: The Fetal Origins Hypothesis.” The Journal of Economic Perspectives 25 (3): 153-172.

Currie, J., Almond, D., 2011. "Human Capital Before Age 5." Handbook of Labor Economics 4 (B): 1315-1486. Eds. David Card and Orley Ashenfelter. Elsevier.

Currie, J., Rossin-Slater, M., 2014. "Early-Life Origins of Life-Cycle Well-Being: Research and Policy Applications.” Journal of Policy Analysis and Management 34(1): 208-242.

Almond, D., and Mazumder, B., 2011. "Health Capital and the Prenatal Environment: The effect of Ramadan Observance During Pregnancy." American Economic Journal: Applied Economics 3 (4): $56-85$.

Andersen, M. L., 2008 "Multiple Inference and Gender Differences in the Effects of Early Intervention: A Reevaluation of Abecedarian, Perry Preschool, and Early Training Programs." Journal of the American Statistical Association 103 (484): 1481-1495.

Barker, D.J.P., 1997. “The Fetal Origins of Coronary Disease.” Acta Paediatrica 86 (S422): 7882.

Ben-Shlomo, Y., Kuh, D., 2002. "A Life Course Approach to Chronic Disease Epidemiology: Conceptual Models, Emperical Challenges and Interdesciplinary Perspectives." International Journal Epidemiology 31: 285-293.

Bernard, S.E., Feindgold, E., 1970. “The Impact of Medicaid.” Wisconsin Law Review 726-755.

Bertrand, M., Duflo, E., Mullainathan S., 2004. "How Much Should We Trust Difference-inDifferences estimates?" Quarterly Journal of Economics 119 (1): 249-275.

Bhalorta, S., Venkataramani, A., 2011. "The Captain of the Men of Death and His Shadow: Long-Run Impacts of Early Life Pneumonia Exposure.” IZA Discussion Paper 6041.

Bharadwaj, P., Katrine Vellesen Løken, and Chris Neilson. 2013. "Early Life Interventions and Academic Achievement.” American Economic Review 103 (5): 1862-1891.

Black, S.E., Devereux, P.J., Salvanes, K.G., 2007. "From the Cradle to the Labor Market? The Effect of Birth Weight on Adult Outcomes." Quarterly Journal of Economics 122 (1): 409-439.

Blackwell, D.L., Hayward, M.D., Crimmins, E.M., 2001. "Does Childhood Health Affect Chronic Morbidity in Later Life?” Social Science \& Medicine 52: 1269-1284.

Bleakley, H., 2007. "Disease and Development: Evidence From Hook Worm Eradication in the American South.” Quarterly Journal of Economics 122 (1): 73-117. 
Brown, D., Kowalski, A.E., Lurie, I.Z., 2014. "Medicaid as an Investment in Children: What is the Long-Term Impact on Tax Receipts?" Monograph. Available at http://www.econ.yale.edu/ ak669/medicaid.latest.draft.pdf

Boudreaux, M., 2014. "The Long-Term Effects of Exposure to Medicaid in Early Childhood." Ph.D. Dissertation. Minneapolis, MN: University of Minnesota.

Campbell, F., Conti, G., Heckman, J.J., Moon, S.H., Pinto, R., Pungello, E., Pan, Y., 2013. "Early Childhood Investments Substantially Boost Adult Health. Science 343: 1478-1485.

Chay, K.Y., Guryan, J., Mazumder, B., 2009. "Birth Cohort and the Black-White Achievement Gap: The Role of Access and Health Soon After Birth." National Bureau of Economic Research (NBER) Working Paper 15078.

Chen, Y., Zhou, L., 2006. "The Long-Term Health and Economic Consequences of the 19591961 Famine in China." Journal of Health Economics 26 (4): 659-681.

Cohen, R.A., Makuc, D.M., Bernstein, A.M., Bilheimer, L.T., Powell-Griner, E., 2009. "Health insurance Coverage Trends, 1959-2007: Estimates from the National Health Interview Survey." National Health Statistics Reports; no 17. Hyattsville, MD: National Center for Health Statistics.

Cohodes, S., Kleiner, S., Lovenheim, M., Grossman, D., 2015. "The Effect of Child Health Insurance Access on Schooling: Evidence from Public Insurance Expansions.” Journal of Human Resources Forthcoming.

Conti, G., Heckman, J.J., Pinto, R., 2015. "The Effects of Two Influential Early Childhood Interventions on Health and Healthy Behaviors." National Bureau of Economic Research (NBER) Working Paper 21454.

Conti, G., Heckman, J.J., Urzua, S., 2010. “The Education-Health Gradient.” American Economic Review: Papers \& Proceedings 100 (2): 234-238.

Cunha, F., Heckman, J.J., "The Technology of Skill Formation.” The American Economic Review 97 (2): 31-47.

Currie, J., 2011. "Inequality at Birth: Some Causes and Consequences." American Economic Journal: Papers \& Proceedings 101(3): 1-22.

Currie, J., Gruber, J., 1996a. "Saving Babies: The Efficacy and Cost of Recent Changes in the Medicaid Eligibility of Pregnant Women.” The Journal of Political Economy 104 (6): 12631296.

Currie, J., Gruber, J., 1996b. "Health Insurance Eligibility, Utilization of Medical Care, and Child Health.” The Quarterly Journal of Economics 111 (2): 431-466.

Currie, J., Decker, S., Lin, W., 2008. "Has Public Insurance for Older Children Reduced Disparities in Access to Care and Health Outcomes?" Journal of Health Economics 27 (6): $1567-$ 1581. 
Dave, D., Decker, S., Kaestner, R., Simon, K., 2008. "Re-examining the Effects of Medicaid Expansions for Pregnant Women." National Bureau of Economic Research (NBER) Working Paper No. 14591.

Davis, K., Schoen, C., 1978. "Health and the War on Poverty: A Ten-Year Appraisal." The Brookings Institution: Washington, DC.

Decker, S.L., Selk, F.W., 2011. "The Effect of the Original Introduction of Medicaid on Welfare Participation and Female Labor Supply." Review of Economics of the Household 10 (4): 541556.

Decker, S.L., Gruber, J., 1993. "The Effect of Medicaid on Access to Health Care and Welfare Participation." PhD Dissertation. Harvard University.

De La Mata, D., 2012. “The Effect of Medicaid Eligibility, Coverage, Utilization, and Children's Health." Health Economics 21 (9): 1061-1079.

Duncan, G.J., Ziol-Guest, K.M., Kalil, A., 2010. "Early-Childhood Poverty and Adult Attainment, Behavior, and Health. Child Development 81(1): 306-325.

Duncan, G.J., Brooks-Gunn, J., Klebanov, P.K., 1994. "Economic Deprivation and Early Childhood Development." Child Development 65(2): 296-318.

Ebrahim, S., Fiona, T., Ward, K., Beswick, A., Burke, M., Smith, G., 2011. "Multiple Risk Factor Interventions for Primary Prevention of Coronary Heart Disease." Cochrane Library.

Figlio D.N., Guryan, J., Karbownik, K., Roth, J., 2014. "The Effects of Poor Neonatal Health on Children's Cognitive Development." American Economic Review 104(12): 3921-3955.

Finkelstein, A., 2007. "The Aggrigate Effects of Health Insurance: Evidence from the Introduction of Medicare.” Quarterly Journal of Economics 122(1):1-37.

Finkelstein, A., Taubman, S., Wright, B., Berstein, M., Gruber, J., Newhouse, J.P., Allen, H., Baiker, K., Oregon Health Study Group, 2012. "The Oregon Health Insurance Experiment: Evidence from the First Year.” Quarterly Journal of Economics 127(3): 1057-1106.

Fitzgerald, J., Gottschalk, P., Moffitt, R.,1998. “An Analysis of Sample Attrition in Panel Data: The Michigan Panel Study of Income Dynamics.” Journal of Human Resources 33 (2): 251-299.

Foltz, A.M., 1975. "The Development of Ambiguous Federal Policy: Early Periodic Screening, Diagnosis and Treatment (EPSDT)." The Milbank Memorial Fund Quarterly 53 (1): 35-64.

Gluckman, P.D., Hanson, M.A., Beedle, A.S., 2007. "Early Life Events and Their Consequences for Later Disease: A Life History and Evolutionary Perspective." American Journal of Human Biology 19 (1):1-19.

Goodman-Bacon, A., 2015. "Public Insurance and Mortality: Evidence from Medicaid Implementation." http://www-personal.umich.edu/ ajgb/medicaid_ajgb.pdf. 
Gouskova, E., Heeringa, S., McGonagle, K., Schoeni, R., Stafford, F., 2008. "Panel Study of Income Dynamics Revised Longitudinal Weights." Survey Research Center-Institute for Social Research, University of Michigan. Technical Paper Series \#08-05.

Holahan, J., 1975. Financing Health Care for the Poor: The Medicaid_Experience (Lexington, MA: Lexington Press).

Howell, Embry M., Genevieve M. Kenny. 2012. "The Impact of Medciaid/CHIP Expansions on Children: A Synthesis of the Evidence." Medical Care Research and Review 69 (4): 372-396.

Hoynes, H.W., Schanzenbach, D.W., 2009. "Consumption Responses to In-Kind Transfers: Evidence Form the Introduction of the Food Stamp Program." American Economic Journal: Applied Economics 1 (4): 109-139.

Hoynes, H.W., Schanzenbach, D.W., Almond, D. 2014. "Long Run Impacts of Childhood Access to the Safety Net." https://gspp.berkeley.edu/assets/uploads/research/pdf/HoynesSchanzenbach-Almond-4-14.pdf

Huxley, R., Neil, A., Collins, R., 2002. "Unraveling the Fetal Origins Hypothesis: Is There Really an Inverse Association between Birth weight and Subsequent Blood Pressure?" Lancet 360 (9334): 659-665

Johnson, R.C., Schoeni, R.F., 2011 "Early-life Origins of Adult Disease: National Longitudinal Population-Based Study of the United Sates." American Journal of Public Health 101 (12): 2317-2324.

Henry J. Kaiser Family Foundation (KFF), 2012. "5 Key Questions on Medicaid and its Role in State/Federal Budgets.” http://kaiserfamilyfoundation.files.wordpress.com/2013/01/8139-02.pdf.

Kermack, W.O., McKendrick, A.G., McKinlay, P.L., 1934. "Death Rates in Great Britain and Sweden. Some General Regularities and Their Significance.” Lancet 31: 698-703.

Lee, D.N., 2013. "The Long Term Effects of Post-Neonatal Childhood Health: Evidence from Mandatory School Vaccination Laws.” http://web.missouri.edu/ leedn/MSVL_DLee.pdf. Accessed: July 1, 2013.

Leininger, L., Levy, H., Schanzenbach, D., 2010. "Consequences of SCHIP Expansions for Household Well-Being.” Forum of Health Economics \& Policy. 13(1): Article 3.

Levine, P.B., Schanzenbach, D., 2009. "The Impact of Children's Public Health Insurance Expansions on Educational Outcomes." Forum for Health Economics and Policy 12 (1): Article 1 .

Markus, A.R., Andres, E., West, K.D., Garro, N., Pellegrini C., 2013. "Medicaid Covered Births, 2008 Through 2010, in the Context of the Implementation of Health Reform." Women's Health Issues 23 (5): e273-e280.

Mazumder, B., Almond, D., Park, K., Crimmins, E.M., Finch, C.E., 2009. "Lingering Effects of the 1918 Influenza Pandemic on Cardiovascular Disease." Journal of Developmental Origins of Health and Disease 1(1): 26-34. 
Miller, S.,Wherry, L., 2015. "The Long-Term Health Effects of Early Life Medicaid Coverage.” http://www-personal.umich.edu/ mille/MillerWherry_Prenatal2015.pdf

Minnesota Population Center and State Health Access Data Assistance Center, 2012. Integrated Health Interview Series: Version 5.0. Minneapolis: University of Minnesota

Montez, J.K., Hayward, M.D., 2011. "Early Life Conditions and Later Life Mortality." In International Handbook of Adult Mortality, Volume 2. Richard G. Rogers and Eileen Crimmins (Eds). Springer.

National Center for Health Statistics, 2012. "Health, United States, 2011: With Special Emphasis on Socioeconomic Status and Health.” Hyattsville, MD.

New York Times, 1966a. "Medicaid Rolls Will Open Today: Applicant May Register at 23 City Welfare Centers." October 3, 1966.

New York Times, 1966b. “Medicaid Notices to be Mailed Oct. 1.” September 17, 1966.

Saloner, B., 2013. "Does Expanding Public Health Insurance Prevent Material Hardship for Families with Children?" Medical Care Research and Review 70 (3): 267-286.

Shonkoff, J., Boyce, T., McEwen, B.S., 2009. "Neuroscience, Molecular Biology, and the Childhood Roots of Health Disparities: Building a New Framework for Health Promotion and Disease Prevention." The Journal of the American Medical Association 201(21): 2252-2259.

Panel Study of Income Dynamics [restricted use data], Produced and distributed by the Survey Research Center, Institute for Social Research, University of Michigan, Ann Arbor, MI (2012).

Royer, H., 2009. "Separated at Girth: US Twin Estimates of the Effects of Birth Weight." American Economic Journal: Applied Economics 1 (1): 49-85.

Schulz, L.C., 2010. "The Dutch Hunger Winter and the Developmental Origins of Health and Disease." Proceedings of the National Academies of Science 107 (39): 16757-16758.

Schwartz, A.L., Sommers, B., 2014. "Moving for Medicaid? Recent Eligibility Expansions Did Not Induce Migration from Other States." Health Affairs 33(1): 88-94.

Shaefer, L.H., Grogan, C.M., Pollack, H.A., 2011. "Transitions from Private to Public Health Coverage among Children: Estimating Effects on Out-of-Pocket Medical Costs and Health Insurance Premium Costs." Health Services Research 46 (3): 840-858.

Social Security Administration, Office of the Historian (SSA), 2013. Personal Communication. Sommers, B.D., Oellerich, D., 2013. “The Poverty-Reducing Effect of Medicaid.” Journal of Health Economics 32 (5): 816-832.

State Health Access Data Assistance Center (SHADAC), 2013. Data Center. http://www.shadac.org/datacenter.

Stevens, R., Stevens, R., 1974. Welfare Medicine in America: A Case Study of Medicaid ( New York, NY: Free Press/MacMillian). 
Strumpf, E., 2011. “Medicaid's Effect on Single Women's Labor Supply: Evidence from The Introduction of Medicaid." Journal of Health Economics 30 (3): 531-548.

U.S. Department of Health, Education, and Welfare (DHEW), 1968. Number of recipients and amounts of payments under Medicaid (Washington DC: National Center for Social Statistics).

U.S. Department of Health Education and Welfare (DHEW), 1970. Characteristics of State Medical Assistance Programs Under Title XIX of the Social Security Act (Washington, DC: U.S. Government Printing Office).

U.S. House Committee on Ways and Means (DHEW), 1996. Background Material and Data on the Programs within the Jurisdiction of the Committee on Ways and Means (Green Book) (Wahsington, DC: U.S. Government Printing Office).

Wherry, L.R., Meyer, B.D., 2015. "Saving Teens: Using a Policy Discontinuity to Estimate Effects of Medicaid Eligibility." Journal of Human Resources. Forthcoming.

Wherry, L.R., Miller, S., Kaestner, R., Meyer, M.B., 2015. "Childhood Medicaid Coverage and Later Life Health Care Utilization." National Bureau of Economic Research (NBER) Working Paper No. 20929. 